Pesq. Vet. Bras. 29(9):767-773, setembro 2009

\title{
Soroprevalência de herpesvírus bovinos tipos 1 e/ou 5 no Estado do Rio Grande do Sul ${ }^{1}$
}

\author{
Carine L.Holz ${ }^{2,4}$, Samuel P. Cibulski², Thais F. Teixeira ${ }^{2,4}$, Helena B.C.R. \\ Batista $^{3,4}$, Fabrício S. Campos ${ }^{3,5}$, Juliana R. Silva ${ }^{2}$, Ana Paula M. Varela ${ }^{2}$, \\ Alexander Cenci $^{2}$, Ana C. Franco ${ }^{3,5}$ e Paulo M. Roehe ${ }^{2,3,4^{*}}$
}

\begin{abstract}
Holz C.L., Cibulski S.P., Teixeira T.F., Batista H.B.C.R., Campos F.S., Silva J.R., Varela A.P.M., Cenci A., Franco A.C. \& Roehe P.M. 2009. [Seroprevalence of bovine herpesvirus types 1 and/or 5 in the state of Rio Grande do Sul.] Soroprevalência de herpesvírus bovinos tipos 1 e/ou 5 no Estado do Rio Grande do Sul. Pesquisa Veterinária Brasileira 29(9):767-773. Instituto de Pesquisas Veterinárias Desidério Finamor, Fepagro Saúde Animal, Estrada do Conde 6000, Cx. Postal 47, Eldorado do Sul, RS 92990-000, Brazil. E-mail: proehe@gmail.com

This study was carried out to estimate the prevalence of antibodies to bovine herpesviruses types 1(BoHV-1) and 5 (BoHV-5) in the state of Rio Grande do Sul (RS), Brazil, by testing serum samples against different BoHV-1 and BoHV-5 strains. The sera examined were obtained from a larger sample designed to estimate the prevalence of bovine brucellosis within the state. All sera were collected from cows 24 months or older, not vaccinated to bovine herpesviruses, from both dairy and beef herds. The number of samples to be tested was calculated based on an estimated prevalence of infection of $33 \%$, with an average standard deviation of $\leq 1 \%$ and a $95 \%$ limit of agreement. Sera from 2.200 cattle from 390 farms distributed in 158 counties were tested by serum neutralization (SN) tests in search for antibodies to the following strains: BoHV-1.1 (strains EVI123/98 and Los Angeles), BoHV-5a (strain EVI88/95) and BoHV-5b (strain A663). The overall seroprevalence to BoHV-1 and BoHV-5 in the sampled herds was $29.2 \%$ (642/2.200); seropositive animals were detected in $225(57.7 \%)$ of the sampled farms. Prevalence estimates varied according to the virus used for challenge in $\mathrm{SN}$ tests. The highest prevalence and sensitivity were attained when positive SN results against the four different strains were added together. The use of only one virus for challenge in SN tests would lead to a loss in sensitivity from $20.4 \%$ to $34.6 \%$ when compared to the combined SN-positive results. These findings provide evidence that antibodies to BoHV1 and BoHV-5 are largely spread in dairy and beef herds in RS, although prevalence in distinct geographic regions is quite variable. The results were strongly affected by the virus strains used for challenge in $\mathrm{SN}$ testing. This must be taken into account when performing serologic tests to detect BoHV-1 and BoHV-5 antibodies. As SN test is not capable of discriminating between antibody responses to BoHV-1 and BoHV-5, typespecific prevalence remains unknown.
\end{abstract}

INDEX TERMS: BoHV-1, BoHV-5, seroprevalence, epidemiology.

\footnotetext{
${ }^{1}$ Recebido em 5 de agosto de 2008.

Aceito para publicação em 1 de junho de 2009.

2 Instituto de Pesquisas Veterinárias Desidério Finamor (IPVDF), Fepagro Saúde Animal, Estrada do Conde 6000, Cx. Postal 47, Eldorado do Sul, RS 92990-000, Brasil. *Autor para correspondência: proehe@gmail.com

${ }^{3}$ Laboratório de Virologia, DM-ICBS/Universidade Federal do Rio
}

\footnotetext{
Grande do Sul (UFRGS), Av. Sarmento Leite 500, sala 208, Porto Alegre, RS 90050-170, Brasil.

${ }^{4}$ Programa de Pós-Graduação em Ciências Veterinárias (PPGCV), Faculdade de Veterinária, UFRGS, Av. Bento Gonçalves 9090, Porto Alegre, RS 9154-000.

${ }^{5}$ Programa de Pós-Graduação em Microbiologia do Meio Ambiente, DM/ICBS/UFRGS, Porto Alegre, RS.
} 
RESUMO.- Este estudo objetivou estimar a prevalência de anticorpos contra os herpesvírus bovinos tipos 1 e 5 (BoHV1 e BoHV-5) no Estado do Rio Grande do Sul (RS), Brasil, frente a diferentes cepas de BoHV-1 e BoHV-5. As amostras de soro utilizadas foram extraídas de uma amostragem mais ampla, desenhada para estimar a prevalência de brucelose bovina no Estado. Todos os soros foram coletados de vacas com idade igual ou superior a 24 meses de idade, não vacinadas contra herpesvírus bovinos, de rebanhos de corte e leite. O cálculo amostral foi baseado em uma expectativa de prevalência média de infecção de $33 \%$, considerando-se um erro padrão não superior a $1 \%$ e um intervalo de confiança de $95 \%$. Com base nesse cálculo foram examinados 2.200 soros, provenientes de 390 propriedades e 158 municípios. Os soros foram analisados na busca de anticorpos contra BoHV-1 e BoHV-5 pela técnica de soroneutralização (SN), executada frente a quatro cepas de vírus distintas: EVI123/98 e Los Angeles (BoHV-1.1); EVI88/95 (BoHV-5a) e A663 (BoHV-5b). A prevalência média de anticorpos contra o BoHV-1 e BoHV-5 nos animais amostrados foi de 29,2\% (642/2200); animais soropositivos foram identificados em $57,7 \%$ (225/390) dos rebanhos. As estimativas de prevalência variaram de acordo com a cepa e/ou vírus utilizado para o desafio nos testes de SN. A prevalência e a sensibilidade mais altas foram obtidas quando os resultados positivos à $\mathrm{SN}$ frente aos quatro vírus distintos foram somados. $\mathrm{O}$ uso de somente um vírus de desafio na SN levaria a redução de sensibilidade de $20,4 \%$ a $34,6 \%$ quando comparada com os resultados positivos combinados. Estes achados evidenciam que anticorpos contra BoHV-1 e BoHV-5 estão amplamente difundidos nos rebanhos do RS, embora a prevalência em distintas regiões geográficas seja bastante variada. Os resultados obtidos nas estimativas de prevalência foram fortemente afetados pelas diferentes amostras de vírus usadas nos testes de SN. Esse fato deve ser levado em consideração quando estudos sorológicos para BoHV-1 e BoHV5 forem realizados. Como a $S N$ não é capaz de discriminar as respostas de anticorpos para BoHV-1 e BoHV-5, a prevalência tipo-específica permanece desconhecida.

TERMOS DE INDEXAÇÃO: BoHV-1, BoHV-5, soroprevalência, epidemiologia.

\section{INTRODUÇÃO}

Os herpesvírus bovinos tipos 1 (BoHV-1) e 5 (BoHV-5) são membros da família Herpesviridae, subfamília Alphaherpesvirinae, gênero Varicellovirus (Roizmann \& Pellett 2007, Thiry et al. 2007). Estes agentes são importantes patógenos responsáveis por significativas perdas econômicas à bovinocultura (Hage et al. 1996). O BoHV-1 tem sido associado a diversas manifestações clínicas em bovinos, incluindo rinotraqueíte infecciosa bovina (IBR), vulvovaginite pustular/balanopostite pustular infecciosa (IPV/IPB), abortos e infecções generalizadas em neonatos (Gibbs \& Rweyemamu 1977, Franco \& Roehe 2007). Ocasionalmente, o BoHV-1 pode ser detectado no sistema nervoso central (SNC) de bovinos, podendo ou não estar relacionado com doença neurológica (Silva et al. 2007). O BoHV-5, por sua vez, é o agente etiológico da encefalite herpética bovina (Murphy et al. 1999, Roizmann \& Pellett 2007), embora possa também induzir sinais de doença respiratória (Schudel et al. 1986, Hübner et al. 2005) e estar igualmente presente no trato genital de bovinos (Esteves et al. 2003, Gomes et al. 2003).

Como característico aos alfaherpesvírus, após a infecção aguda, tanto BoHV-1 quanto o BoHV-5 estabelecem infecções latentes, alojando-se em gânglios nervosos sensoriais (Jones 2003). Este fenômeno leva à esporádica reativação de vírus infeccioso e sua disseminação, determinando assim a perpetuação da infecção nos rebanhos (Thiry et al. 1985, Franco \& Roehe 2007).

O BoHV-1 possui distribuição mundial amplamente demonstrada em diversos estudos. A prevalência de infecções por BoHV-1 em rebanhos bovinos atinge taxas variadas em diferentes rebanhos e regiões (Straub 2001). Já o BoHV-5 possui uma distribuição geográfica aparentemente mais restrita. São poucos os registros de infecções por BoHV-5 no hemisfério norte (D'Offay et al. 1993, D’Arce et al. 2002). Ao contrário, no hemisfério sul, especialmente Brasil e Argentina (onde tem sido conduzida a maior parte dos estudos com BoHV-5), o número de amostras de BoHV-5 isoladas tem sido bastante significativo (Souza et al. 2002; D’Arce et al. 2002; Silva et al. 2007, Esteves et al. 2007).

De fato, até o presente, todos os estudos de soroprevalência de herpesvírus bovinos realizados no País foram executados somente frente a cepas de BoHV-1, não buscando animais soropositivos para o BoHV-5 (Ravazzolo et al.1989, Lovato et al. 1995, Vidor et al. 1995, Lage et al. 1996, Melo et al. 1997, Cerqueira et al. 2000, Médici et al. 2000, Vieira et al. 2003, Poletto et al. 2004, Barbosa et al. 2005). Além disso, os estudos prévios foram realizados frente a somente uma determinada cepa de vírus, normalmente uma amostra "referência" de BoHV-1. Estudos recentes realizados por nosso grupo evidenciaram que a soroprevalência pode ser significativamente afetada pelo uso de distintas cepas de vírus como vírus de desafio em testes de soroneutralização (Holz et al. 2008). Em vista disso, esse estudo foi realizado buscando estimar a soroprevalência das infecções por BoHV-1 e/ou BoHV-5 no Estado do Rio Grande do Sul frente a diferentes cepas destes vírus, objetivando uma maior eficácia e sensibilidade. Para tanto, foram utilizadas quatro cepas de herpesvírus bovinos, em testes sobre uma amostragem considerada significativa da população de fêmeas bovinas adultas (>24 meses), não vacinadas contra o BoHV-1 ou BoHV-5.

\section{MATERIAL E MÉTODOS}

\section{Amostragem}

O presente estudo foi realizado utilizando amostras de soro coletadas para um levantamento epidemiológico desenhado para avaliar a prevalência de brucelose (Paulin \& Neto 2002, Poester et al. 2002). Sobre estas foi efetuado um novo cálculo 
amostral baseado em uma expectativa de prevalência de infecções por BoHV-1 e BoHV-5 da ordem de 33\%, considerando um erro padrão não superior a $1 \%$ e um intervalo de confiança de $95 \%$, calculado segundo Noordhuizen et al. (1997). Desta forma, foi estimado um número mínimo de 2178 amostras de soro. Com base nos dados estimados pelo IBGE (2006) para a população bovina do RS foi selecionado um número de amostras de soro proporcional ao tamanho do rebanho de cada meso/ microrregião do RS, a fim de proporcionar uma maior representatividade do Estado. De acordo com o IBGE, o Estado é subdividido em 7 mesorregiões e 35 microrregiões (Quadro 1), dos quais foram selecionados aleatoriamente de 1 a 15 soros das 390 propriedades pertencentes a 158 municípios do RS. Foram excluídas da seleção as amostras provenientes de rebanhos onde a vacinação contra BoHV-1 era praticada. Todas as

\section{Quadro 1. População bovina do Rio Grande do Sul distribuída em meso e microrregiões (IBGE, 2006) e total de amostras analisadas no presente estudo}

Meso e microrregiões do RS População \% da popula- Total bovina ção bovina amostras (cabeças) total do RS analisadas

\begin{tabular}{|c|c|c|c|}
\hline Centro Ocidental & 1576814 & 11,28 & 248 \\
\hline Santiago & 610304 & 4,37 & 96 \\
\hline Santa Maria & 823995 & 5,90 & 130 \\
\hline Restinga Seca & 142515 & 1,02 & 22 \\
\hline Centro Oriental & 853509 & 6,11 & 134 \\
\hline Santa Cruz do Sul & 219448 & 1,57 & 35 \\
\hline Lajeado-Estrela & 219411 & 1,57 & 35 \\
\hline Cachoeira do Sul & 414650 & 2,97 & 65 \\
\hline Metropolitana de Porto Alegre & 1087532 & 7,78 & 171 \\
\hline Montenegro & 81896 & 0,59 & 13 \\
\hline Gramado-Canela & 75555 & 0,54 & 12 \\
\hline São Jerônimo & 207648 & 1,49 & 33 \\
\hline Porto Alegre & 192275 & 1,38 & 30 \\
\hline Osório & 335488 & 2,40 & 53 \\
\hline Camaquã & 194670 & 1,39 & 31 \\
\hline Nordeste & 870117 & 6,23 & 137 \\
\hline Guaporé & 152338 & 1,09 & 24 \\
\hline Vacaria & 570705 & 4,08 & 90 \\
\hline Caxias do Sul & 147074 & 1,05 & 23 \\
\hline Noroeste & 2654287 & 18,99 & 418 \\
\hline Santa Rosa & 207548 & 1,49 & 33 \\
\hline Três Passos & 212769 & 1,52 & 33 \\
\hline Frederico Westphalen & 287482 & 2,06 & 45 \\
\hline Erechim & 266846 & 1,91 & 42 \\
\hline Sananduva & 129976 & 0,93 & 20 \\
\hline Cerro Largo & 158016 & 1,13 & 25 \\
\hline Santo Ângelo & 573691 & 4,11 & 90 \\
\hline ljuí & 141152 & 1,01 & 22 \\
\hline Carazinho & 117465 & 0,84 & 18 \\
\hline Passo Fundo & 188616 & 1,35 & 30 \\
\hline Cruz Alta & 197333 & 1,41 & 31 \\
\hline Não-Me-Toque & 39042 & 0,28 & 6 \\
\hline Soledade & 134351 & 0,96 & 21 \\
\hline Sudeste & 2193382 & 15,70 & 345 \\
\hline Serras de Sudeste & 958627 & 6,86 & 151 \\
\hline Pelotas & 522857 & 3,74 & 82 \\
\hline Jaguarão & 322032 & 2,30 & 51 \\
\hline Litoral Lagunar & 389866 & 2,79 & 61 \\
\hline Sudoeste & 4739186 & 33,91 & 746 \\
\hline Campanha Ocidental & 2120329 & 15,17 & 334 \\
\hline Campanha Central & 1401559 & 10,03 & 221 \\
\hline Campanha Meridional & 1217298 & 8,71 & 192 \\
\hline Total & 13974827 & & 2200 \\
\hline
\end{tabular}

amostras de soro foram inativadas em banho-maria a $56^{\circ} \mathrm{C}$ por 30 min e estocadas $\mathrm{a}-20^{\circ} \mathrm{C}$ até o momento do uso.

\section{Células e vírus}

As cepas de vírus e células foram obtidas dos estoques do Instituto de Pesquisas Veterinárias Desidério Finamor (IPVDF). Para a sorologia foram utilizadas células de rim de bovino Madin Darby Bovine Kidney (MDBK, originária da ATCC; CCL-22) cultivadas em meio mínimo essencial de Eagle (MEM; Gibco) suplementadas com $10 \%$ de soro fetal bovino (SFB; Soraly) e antibióticos (Penicilina e Estreptomicina) em concentrações usuais (Paul 1970). Todos os meios e soros foram previamente testados para assegurar a ausência de vírus da diarréia viral bovina (BVDV) e herpesvírus bovinos (Oliveira et al. 1996; Franco \& Roehe 2007). As células foram repicadas a cada 3-4 dias e cultivadas seguindo métodos estabelecidos na literatura (Paul 1970).

Foram utilizadas cepas de vírus de diferentes tipos e subtipos de BoHV-1 e BoHV-5. Estas foram selecionadas em testes prévios, em função de haverem detectado $99 \%$ de soros positivos em outro estudo com amostras de soros da mesma região (Holz 2008). As amostras virais utilizadas foram: BoHV-1.1. Los Angeles (LA; Madin et al. 1956), BoHV-1.1. EVI123/98 (Roehe et al. 1997, Souza et al. 2002), BoHV-5b A663 (BoHV-5b; Carrillo et al. 1983, D'Arce et al. 2002) e BoHV-5a EVI88/95 (Roehe et al. 1997, Souza et al. 2002). A multiplicação e titulação das cepas virais foram realizadas em células MDBK como descrito previamente (Roehe et al. 1997).

\section{Testes de soroneutralização}

A pesquisa de anticorpos neutralizantes para BoHV-1 e BoHV-5 foi realizada frente a cada uma das quatro amostras de vírus mencionadas acima, individualmente, utilizando a técnica de soroneutralização (SN) em microplacas de 96 orifícios, como descrito previamente (Deregt et al. 1993), com diluições $1 / 2$ e $1 / 4$ de cada soro e incubação da mistura soro-vírus de uma hora antes da adição das células. As placas foram incubadas a $37^{\circ} \mathrm{C}$ em atmosfera contendo $5 \%$ de $\mathrm{CO}_{2}$ por até $120 \mathrm{~h}$ para a leitura final dos resultados, realizada pela observação da presença ou ausência de efeito citopático. Os resultados foram calculados pelo método de Reed e Müench (Lorenz \& Bögel 1973) e expressos como positivo (título $\geq 2$ ) ou negativo (título $<2)$

\section{Análise estatística}

Foi realizado o cálculo da sensibilidade dos testes de SN utilizando-se os resultados de uma, duas, três ou quatro diferentes cepas virais. O cálculo foi realizado através do programa Dag Stat (Mackinnon 2000) com intervalo de confiança de $95 \%$.

\section{RESULTADOS E DISCUSSÃO}

Das 2200 amostras examinadas, 29,2\% (642) foram positivas frente a pelo menos uma das quatro cepas de vírus utilizadas nos testes de SN (Quadro 2). Do total de 390 propriedades testadas contra o BoHV-1 e BoHV-5, foram identificados animais reagentes em 225 (57,7\%). Quando examinada a soroprevalência nas diferentes mesorregiões do Estado (Quadro 1, Fig.1), observa-se que a mesorregião que apresentou maior soroprevalência foi a Nordeste (36,5\%), seguida da Metropolitana de Porto Alegre $(34,5 \%)$. Uma taxa de soroprevalência acima da média foi igualmente 
Quadro 2. Resultados dos testes de soroneutralização frente a diferentes cepas de herpesvírus bovinos tipos 1 (BoHV-1 ) e 5 (BoHV-5) em amostras de soros bovinos coletados no Estado do Rio Grande do Sul e estimativa da sensibilidade e da prevalência da infecção de acordo com o(s) vírus utilizado(s)

\begin{tabular}{|c|c|c|c|c|}
\hline Tipos/subtipos de vírus & $\begin{array}{l}\text { Cepa frente a qual } \\
\text { foi realizada a SN }\end{array}$ & $\begin{array}{l}\text { Amostras } \\
\text { positivas }\end{array}$ & $\begin{array}{l}\text { Sensibilidade } \\
\text { estimada }\end{array}$ & Prevalência \\
\hline BoHV-1.1 & LA & 482 & $75 \%$ & 21,9 \\
\hline BoHV-1.1 & EVI123* & 511 & $79,6 \%$ & 23,2 \\
\hline BoHV-5a & EVI88** & 420 & $65,4 \%$ & 19,1 \\
\hline BoHV-5b & A663 & 484 & $75,4 \%$ & 22,0 \\
\hline BoHV-1.1 + BoHV-1.1 & $L A+E V I 123$ & 595 & $92,7 \%$ & 27,0 \\
\hline BoHV-1.1 + BoHV-5a & $L A+E V I 88$ & 553 & $86 \%$ & 25,1 \\
\hline BoHV-1.1 + BoHV-5a & $L A+A 663$ & 558 & $87 \%$ & 25,4 \\
\hline BoHV-1.1 + BoHV-5a & EVl123 + EVI88 & 567 & $88,3 \%$ & 25,8 \\
\hline BoHV-1.1 + BoHV-5b & EVI123 + A663 & 590 & $91,9 \%$ & 26,8 \\
\hline BoHV-5a + BoHV-5b & EVI88 + A663 & 538 & $83,8 \%$ & 24,5 \\
\hline BoHV-1.1 + BoHV-1.1 + BoHV-5a & LA + EVI123 + EVI88 & 620 & $96,5 \%$ & 28,2 \\
\hline BoHV-1.1 + BoHV-1.1 + BoHV-5b & $\mathrm{LA}+\mathrm{EVI} 123+\mathrm{A} 663$ & 623 & $97 \%$ & 28,3 \\
\hline BoHV-1.1 + BoHV-5a + BoHV-5b & $L A+E V I 88+A 663$ & 593 & $92,4 \%$ & 27,0 \\
\hline BoHV-1.1 + BoHV-5a + BoHV-5b & $E V I 123+E V I 88+A 663$ & 611 & $95,2 \%$ & 27,8 \\
\hline BoHV-1.1 + BoHV-1.1+ BoHV-5a + BoHV-5b & $L A+E V I 123+E V I 88+A 663$ & 642 & $100 \%$ & 29,2 \\
\hline
\end{tabular}

* Refere-se à amostra EVI123/98 (vide métodos); ** Refere-se à amostra EVI88/95 (vide métodos); Sensibilidade calculada com intervalo de confiança de $95 \%$.

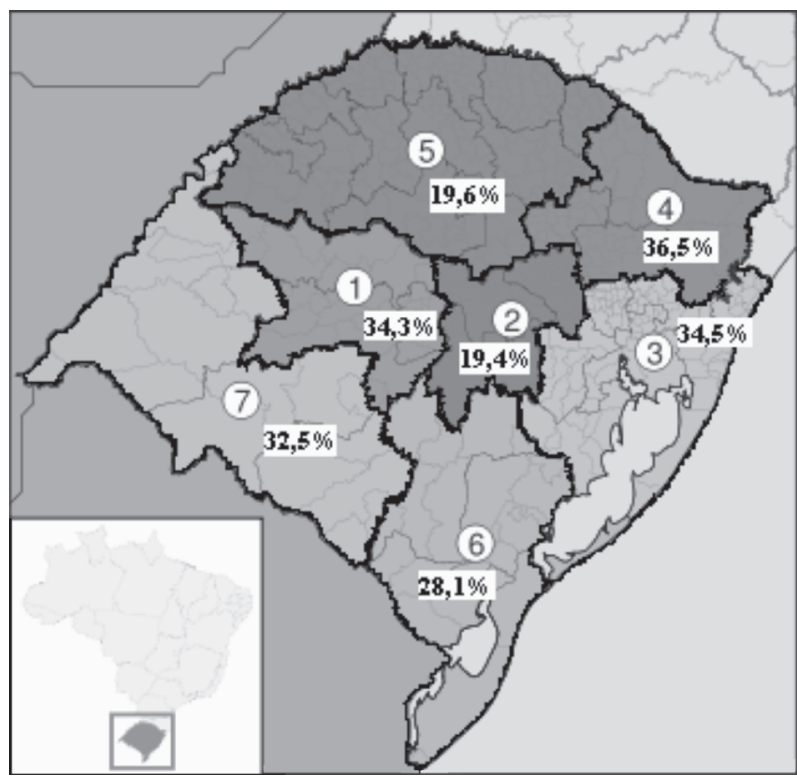

Fig.1. Soroprevalência de herpesvírus bovinos tipos 1 e 5 de acordo com as mesorregiões do Estado do Rio Grande do Sul. Soroprevalência média, expressa em percentagens calculadas sobre o total de amostras examinadas em cada mesorregião. Mesorregiões (números em círculos):(1) Centro Ocidental, (2) Centro Oriental, (3) Metropolitana de Porto Alegre, (4) Nordeste, (5) Noroeste, (6) Sudeste, (7) Sudoeste.

detectada nas mesorregiões Centro Ocidental (34,5\%) e Sudoeste (32,5\%). As mesorregiões Noroeste e CentroOriental, assim como o Sudeste, apresentaram índices abaixo da média do Estado (Fig.1). As diferenças nas taxas de prevalência para as diferentes mesorregiões do RS podem provavelmente ser explicadas, em parte, pelo tipo de criação e manejo dos animais, que variam bastante nas diferentes mesorregiões. Além disso, fatores climáticos e geo- gráficos, o tipo de população amostrada, e o tipo de exploração utilizado na propriedade (Lovato et al. 1995) também podem influenciar as taxas observadas. Lovato et al. (1995) detectaram na região de Passo Fundo (dentro da mesorregião Noroeste), prevalência de infecções por BoHV-1 ou BoHV-5 de cerca de $12 \%$, sendo aquela a região que apresentou os menores índices de soropositividade naquele levantamento. No presente estudo, aquela região apresentou coeficiente de soropositividade de $19,6 \%$, superior ao detectado por Lovato et al. (1995), mas ainda um dos mais baixos índices encontrados no presente estudo - não obstante coerente com o uso de múltiplas amostras de vírus nos testes laboratoriais aqui realizados.

Esses achados foram, de certa forma, surpreendentes, pois os autores esperavam encontrar índices mais elevados de soroprevalência, visto que várias amostras de vírus foram utilizadas para garantir uma maior sensibilidade à SN. A exclusão de machos da amostragem certamente deve ter tido um efeito importante nas soroprevalências obtidas, pois em função da monta e do tempo em que permanecem em contato com o rebanho, este é o grupo de animais que tende a apresentar maiores taxas de soropositividade (Melo et al. 2002, Dias et al. 2006). Assim, os resultados aqui obtidos também podem ter sido afetados pelo tipo de amostragem.

O presente trabalho difere dos anteriores principalmente porque o cálculo amostral foi baseado em dados referentes à distribuição da população bovina por meso e microrregiões do Estado (IBGE 2006), semelhante ao enfoque adotado por Dias et al. (2008). Portanto, as heterogeneidades regionais de cada estudo podem ter tido influência nas taxas de prevalência encontradas. Além disso, no presente trabalho foram examinadas somente fêmeas adultas (>24 meses), categoria animal em que estas infecções tendem a ser mais prevalentes pela mai- 
or disseminação durante a temporada de monta (Melo et al. 2002, Dias 2006).

Além dos fatores mencionados acima, foi demonstrado que as diferenças em prevalência podem também estar relacionadas com as cepas de vírus utilizadas para os testes laboratoriais, o que pode levar a alterações na sensibilidade da SN. No Brasil, a quase totalidade dos inquéritos sorológicos previamente realizados utilizaram uma das cepas de "referência" de BoHV-1 como vírus de desafio no teste sorológico (Galvão et al. 1963, Wizigmann et al. 1972, Mueller et al. 1981, Ravazzolo et al. 1989, Lovato et al. 1995, Vidor et al. 1995, Melo et al. 1997, Cerqueira et al. 2000, Médici et al. 2000, Rocha et al. 2001, Quincozes 2005, Dias 2006, Dias et al. 2008). No presente estudo foi demonstrado que, para que seja obtida uma maior sensibilidade, os testes de SN devem ser executados frente a várias amostras de vírus.

Quando considerados os resultados dos testes obtidos frente a cada uma das amostras de vírus isoladamente, a prevalência encontrada revelou uma grande redução de sensibilidade dependendo da amostra/cepa considerada, pois $20,4 \%$ a $34,6 \%$ das amostras soropositivas seriam consideradas negativas se o teste fosse realizado contra somente uma delas (Quadro 2). A cepa viral que, isoladamente, foi reconhecida pelo maior número de amostras positivas nesse estudo foi a EVI123/98 (BoHV-1.1), uma cepa autóctone de BoHV-1 (Roehe et al. 1997, Souza et al. 2002). Esta cepa reagiu com $79,5 \%$ das amostras, seguida pela amostra de BoHV-5b A663, que reagiu com 70,4\% e a amostra Los Angeles (LA) de BoHV-1, que reagiu com $70 \%$ do total de soros positivos. Epidemiologicamente, esse elevado número de "falsos negativos" pode representar uma falha importante na detecção de animais potencialmente disseminadores da infecção, o que poderia comprometer eventuais tentativas de controle ou erradicação (Ackermann et al. 1990, Del Fava et al. 1998).

Foi possível perceber que houve reatividade sorológica cruzada na maioria dos soros positivos detectados (Fig. 2). Das 642 amostras soropositivas para pelo menos uma

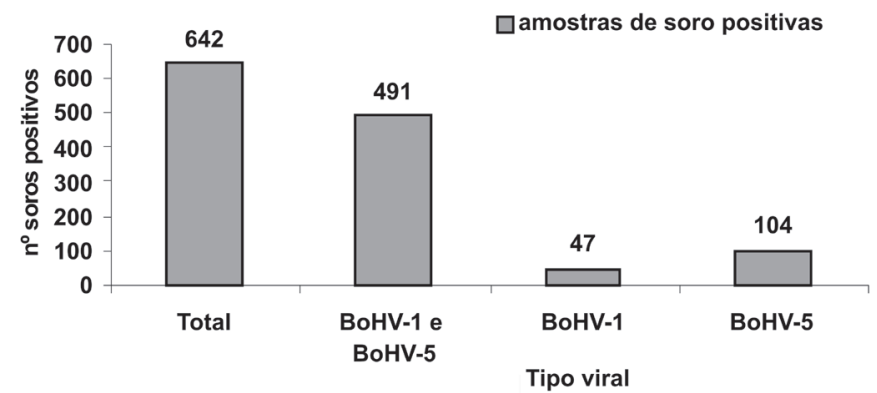

Fig. 2. Análise das respostas de anticorpos tipo-específicas para BoHV-1 e BoHV-5 em testes de soroneutralização. São apresentados o total de amostras positivas $(n=642)$, soros com reatividade cruzada frente aos herpesvírus bovinos tipos 1 (BoHV-1) e 5 (BoHV-5) e soros com reatividade tipoespecífica. das cepas virais analisadas, 491 foram positivas tanto para cepas de BoHV-1 quanto para cepas de BoHV-5. Somente 151 soros apresentaram reações tipo-específicas, sendo 104 soros positivos apenas para amostras de BoHV5 e 47 positivos apenas para amostras de BoHV-1. Assim, a SN não apresentou sensibilidade capaz de discriminar as respostas sorológicas tipo-específicas. Em estudo prévio (Teixeira et al. 1998), havia sido demonstrado que mesmo titulações de anticorpos séricos por SN não eram capazes de discriminar respostas tipo-específicas. Naquela ocasião, cerca de $8 \%$ dos soros apresentaram reações tipo-específicas, tanto para BoHV-1 como para BoHV-5; no presente estudo, uma precentagem similar de soros apresentou anticorpos tipo-específicos antiBoHV-1 (47 soros, ou 7,32\%). Por outro lado, 104 soros $(16,19 \%)$ reagiram especificamente contra amostras de BoHV-5. Estes resultados comprovam que a SN não apresenta poder discriminatório suficiente para revelar reaçõaes tipo-específicas. Além disso, corroboram a necessidade de utilizar tanto amostras de BoHV-1 como BoHV-5 em estudos onde máxima sensibilidade à SN seria o resultado esperado. Não se deve, entretanto, deixar de cogitar a possibilidade de que parte desses resultados pode representar animais infectados concomitantemente com o BoHV-1 e BoHV-5.

Não obstante, estes resultados revelam que anticorpos contra BoHV-1 (como já esperado) e/ou BoHV-5 estão amplamente difundidos nos rebanhos do Estado, embora a prevalência nas distintas mesorregiões do Estado seja bastante variada. Relevante, porém, é o fato de que as estimativas de prevalência foram fortemente afetadas pelas diferentes amostras de vírus usadas nos testes de SN. Esse fato deve ser levado em consideração quando estudos sorológicos para BoHV-1 e BoHV-5 forem realizados, especialmente se forem realizados tendo em vista a tomada de medidas de controle ou erradicação, onde a ocorrência de falsos negativos pode ser decisiva para o êxito do processo .

A determinação das taxas de prevalência tipo-específicas não pode ser realizada. No entanto, foi possível perceber que é importante realizar os testes de SN frente a amostras de BoHV-1 e BoHV-5, no intuito de aumentar a detecção de amostras soropositivas. Infelizmente, como a SN não é capaz de discriminar as respostas de anticorpos para BoHV1 e BoHV-5, a prevalência tipo-específica permanece desconhecida, e deverá ser objeto de estudos futuros.

Agradecimentos.- À Secretaria Estadual de Agricultura, Pecuária e Agronegócio do Rio Grande do Sul e a Maurício G. Dasso pelo gentil cedimento das amostras de soro. Ao Núcleo de Estatística da Universidade Federal do Rio Grande do Sul, pelo auxílio na análise dos dados. Apoio financeiro: CNPq, Fepagro, FAPERGS, CAPES. Carine L. Holz é mestranda; Thais F. Teixeira, Diógenes Dezen e Helena B.C.R. Batista são doutorandos do Programa de Pós-graduação em Ciências Veterinárias da UFRGS; Fabrício S. Campos é mestrando do Programa de Pós-graduação em Microbiologia Agrícola e do Ambiente da UFRGS; Samuel P. Cibulski, Luciana R. Roehe, Martha T. Oliveira e Ana Paula M. Varela são estagiários de Iniciação Científica; Paulo M. Roehe é bolsista pesquisador $1 \mathrm{C}$ do $\mathrm{CNPq}$. 


\section{REFERÊNCIAS}

Ackermann M., Müller H.K., Bruckner L. \& Kihm U. 1990. Eradication of infectious bovine rhinotracheitis in Switzerland: Review and prospects. Vet. Microbiol. 23:365-370.

Barbosa A.C.V.C., Brito W.M.E.D. \& Alfaia B.T. 2005. Soroprevalência e fatores de risco para a infecção pelo herpesvírus bovino tipo 1 (BHV1) no Estado de Goiás, Brasil. Ciência Rural 35(6):1368-1373.

Carrillo B.J., Ambrogi A., Schudel A.A., Vazquez M., Dahme E. \& Pospichil A. 1983. Meningoencephalitis caused by IBR virus in calves in Argentina. Zentralbl. Veterinärmed. B 30:327-332.

Cerqueira R.B., Carminati R., Silva J.M., Soares G.C., Meyer R. \& Sardi S. 2000. Serological survey for bovine herpesvirus 1 in cattle from different regions in the state of Bahia, Brazil. Braz. J. Vet. Res. Anim. Sci. 37(6):497-500.

D'Arce R.C.F., Almeida R.S., Silva T.C., Franco A.C., Spilki F.R., Roehe P.M. \& Arns C.W. 2000. Restriction endonuclease and monoclonal antibody analysis of Brazilian isolates of bovine herpesviruses types 1 and 5. Vet. Microbiol. 88(4):315-324.

Del Fava C., Stefano E., Pituco E.M., Bilinskyj M.C.V., Okuda L.H., Pozzi C. R., Veríssimo C.J. \& Demarchi J.J.A.A.1998. Erradicação do herpesvírus bovino-1 (BHV-1) de um rebanho bovino leiteiro em manejo semi-intensivo. Pesq. Vet. Bras. 18(2):65-68.

Deregt D., Cho H.J.C. \& Kozub G.C. 1993. A comparative evaluation of two sensitive serum neutralization tests for bovine herpesvirus-1 antibodies. Can. J. Vet. Res. 57:56-59.

D'Offay J.M., Mock R.E. \& Fulton R.W. 1993. Isolation and characterization of encephalitic bovine herpesvirus type 1 isolates from cattle in North America. Am. J. Vet. Res. 54(4):534-539.

Dias M.M. 2006. Avaliação do estresse do desmame em bezerros de corte e sua relação com o performance produtivo. Tese de doutorado, Programa de Pós Graduação em Ciências Veterinárias, Universidade Federal do Rio Grande do Sul, Porto Alegre.

Dias J.A., Alfieri A.A., Médici K.C., Freitas J.C., Ferreira Neto J.S. \& Müller E. 2008. Fatores de risco associados à infecção pelo herpesvírus bovino $1 \mathrm{em}$ rebanhos bovinos da região Oeste do Estado do Paraná. Pesq. Vet. Bras. 28(3):161-168

Esteves P.A., Dellagostin O.A., Pinto L.S., Silva A.P., Spilki F.R., CiacciZanella J.R., Hübner S.O., Puentes R., Maisonnave J., Franco A.C., Rijsewijk F.A.M., Batista H.B.C.R., Teixeira T.F., Dezen D., Oliveira A.P., David C., Arns C.W. \& Roehe P.M. 2007. Philogenetic comparison of the carboxy-terminal region of glycoprotein $C(\mathrm{gC})$ of bovine herpesviruses (BoHV) 1.1, 1.2 and 5 from South America (SA). Virus Res. 131(1):16-22.

Franco A.C. \& Roehe P.M. 2007. Herpesviridae, p.433-488. In: Flores E.F. (Ed.), Virologia Veterinária. Editora UFSM, Santa Maria.

Gibbs E.P.J. \& Rweyemamu M.M. 1977. Bovine herpesvirus. Part I. Vet. Bull. 47(5):317-343.

Gomes L.I., Rocha M.A., Souza J.G., Costa E.A. \& Barbosa-Stancioli E.F. 2003. Bovine herpesvirus 5 (BoHV-5) in bull semen: Amplification and sequence analysis of the US4 gene. Vet. Res. Comm. 27(6):495504.

Hage J.J., Schukken Y.H., Barkema H.W., Benedictus G., Rijsewijk F.A. \& Wentink G.H. 1996. Population dynamics of bovine herpes 1 infection in a dairy herd. Vet. Microbiol. 53:169-180.

Halfen D.C. \& Vidor T. 1998. Infecção por herpesvírus bovino 1 e herpesvírus bovino 5, p.82-91. In: Riet-Correa F., Schild A.L. \& Méndez M.C. (Eds), Doenças de Ruminantes e Eqüinos. Editora Universitária, UFPel, Pelotas, RS.

Holz C.L. 2008. Otimização da soroneutralização com diferentes tipos e subtipos de herpesvírus bovinos e sua aplicação à epidemiologia. Dissertação de Mestrado em Ciências Veterinárias, Universidade Federal do Rio Grande do Sul, Porto Alegre.

Hübner S.O., Oliveira A.P., Franco A.C., Esteves P.A., Silva A.D., Spilki
F.R., Rijsewijk F.A. \& Roehe P.M. 2005. Experimental infection of calves with a gl, gE, US9 negative bovine herpesvirus type 5. Comp. Immunol. Microbiol. Infect. Dis. 28:187-196.

IBGE 2006. Pesquisa da Pecuária Municipal 2006. Instituto Brasileiro de Geografia e Estatística. http://www.ibge.gov.br. Acesso em 25.11.2007.

Jones C. 2003. Herpes simplex virus type 1 and bovine herpesvirus 1 latency. Clin. Microbiol. Rev. 16(1):79-95.

Lage A.P., Castro R.S., Melo M.I.V., Aguiar P.H.P., Filho J.B.B. \& Leite R.C. 1996. Prevalence of antibodies to bluetongue, bovine herpesvirus 1 and bovine viral diarrhea/mucosal disease viruses in water buffaloes in Minas Gerais State, Brazil. Rev. d’Elev. Méd. Vét. Pays Tropic. 49(3):195-197.

Lorenz R.J. \& Bögel K. 1973. Methods of calculation, p.329-332. In: Kaplan M.M. \& Koprowsky H. (Eds), Laboratory Tecniques in Rabies. World Health Organization, Geneva.

Lovato L.T., Weiblen R., Tobias F.L. \& Moraes M.P. 1995. Herpesvírus bovino tipo 1 (HVB-1): inquérito soro-epidemiológico no rebanho leiteiro do estado do Rio Grande do Sul, Brasil. Ciência Rural 25(3):425430 .

MacKinnon A. 2000. A spreadsheet for the calculation of comprehensive statistics for the assessment of diagnostic tests and inter-rater agreement. Comput. Biol. Med. 30(3):127-134.

Madin S.H., York C.J. \& McKercher D.G. 1956. Isolation of the infectious bovine rhinotracheitis virus. Science 129(1):721-722.

Médici K.C., Alfieri A.A. \& Alfieri A.F. 2000. Prevalência de anticorpos neutralizantes contra o herpesvírus bovino tipo 1 , decorrentes de infecção natural, em rebanhos com distúrbios reprodutivos. Ciência Rural 30(2):347-350

Melo C.B., Oliveira A.M., Figueiredo H.C.P., Leite R.C. \& Lobato Z.I.P. 1997. Prevalência de anticorpos contra Herpesvírus bovino-1, vírus da diarréia viral bovina e vírus da leucose enzoótica bovina em bovinos do Estado de Sergipe, Brasil. Revta Bras. Reprod. Anim. 21(2):160161.

Melo C.B., Lobato Z.I.P., Camargos M.F., Souza G.N., Martins N.R.S. \& Leite R.C. 2002. Distribuição de anticorpos para herpesvírus bovino 1 em rebanhos bovinos Arq. Bras. Med. Vet. Zootec. 54(6). doi: 10.1590/S0102-09352002000600003. Acesso em 28.7.2008.

Murphy F.A., Gibbs E.P., Horzinek M.C. \& Studdert M.J. 1999. Veterinary Virology. 3rd ed. Academic Press, New York.

Noordhuizen J.P.T.M., Frankena K., van der Hoofd C.M. \& Graat E.A.M. 1997. Application of quantitative methods in veterinary epidemiology. Wageningen Press, Wageningen. 445p.

Odeon A.C. 1998. Herpesvirus Bovino. Anais do Simpósio Internacional sobre Herpesvírus Bovino (Tipo 1 e 5) e Vírus da Diarréia Viral Bovina (BVDV), Santa Maria, RS, p.103-111.

Oliveira L.G., Oliveira E.A.S., Silva L.H.T., Vieira L.A. Hoffmann V.L., Fernandes G.V., Silva T.C., Caldas A.P.F. \& Roehe P.M. 1996. Presença de pestivírus e anticorpos contra pestivírus em soros e cultivos celulares. Arq. Bras. Med. Vet. Zootec. 48(5):513-521

Paul J. 1970. Cell and Tissue Cultures. 4th ed. E. and S., Livingstone, London.

Paulin L.M. \& Neto J.S.F.A. 2002. Experiência brasileira no combate à brucelose bovina. Arqs Inst. Biológico, São Paulo, 69(2):105-112.

Poester F.P., Gonçalves V.S.P. \& Lage A.P. 2002. Brucellosis in Brazil. Vet. Microbiol. 90:55-62.

Poletto R., Kreutz L.C., Gonzales J.C. \& Barcellos L.J.G. 2004. Prevalência de tuberculose e infecções víricas em bovinos leiteiros do município de Passo Fundo, RS. Ciência Rural 34(2):595-598.

Quincozes C. 2005. Prevalência e fatores de risco associados às infecções pelos herpesvírus bovino tipo 1 e tipo 5 (BoHV-1 e 5) e pelo vírus da diarréia viral bovina (BVDV) nos rebanhos dos municípios de Santa Vitória do Palmar e Chuí. Dissertação de Mestrado, Faculdade de Veterinária, Universidade Federal de Pelotas. 
Ravazzolo A.P., Dal Pizzol M. \& Moojen V. 1989. Evidência da presença de anticorpos para o vírus da rinotraqueíte infecciosa dos bovinos em alguns municípios do Estado do Rio Grande do Sul. Arq. Fac. Vet. UFRGS 17:98-95.

Rocha M.A., Gouveia A.M.G., Lobato Z.I.P. \& Leite R.C. 2001. Pesquisa de anticorpos para IBR em amostragem de demanda no Estado de Minas Gerais, 1990-1999. Arq. Bras. Med.Vet. Zootec. 53(6):645-647.

Roehe P.M., Silva T.C., Nardi N.B., Oliveira L.G. \& Rosa J.C.A. 1997. Diferenciação entre os vírus da rinotraqueíte infecciosa bovina (BHV1) e vírus da encefalite bovina (BHV-5) com anticorpos monoclonais. Pesq. Vet. Bras. 17(1):41-44.

Roizmann B. \& Pellett P.E. 2007. The family Herpesviridae, a brief introduction, p. 2480-2497. In: Knipe, M.D. \& Howley, P.M. Field's Virology. 5th ed. Lippincott Williams and Wilkins, Philadelphia.

Schudel A.A., Carrillo B.J., Wyler R.\& Metzler N.L. 1986. Infections of calves with antigenic variants of bovine herpesvirus type 1 (BHV-1) and neurological disease. Zentralbl. Veterinärmed. B 33:303-310.

Silva M.S., Brum M.C.S., Loreto E.L.S., Weiblein R. \& Flores E.F. 2007. Molecular and antigenic characterization of Brazilian bovine herpesvirus type 1 isolates recovered from the brain of cattle with neurological disease. Virus Res. 129:191-199.

Souza V.F., Melo S.V., Esteves P.A., Schmidt C.S., Gonçalves D.A., Schaefer R., Silva, T.C., Almeida R.S., Vicentini F., Franco A.C., Oliveira E.A., Spilki F.R., Weiblein R., Flores E.F., Lemos R.A., Alfieri A.A., Pituco E.M. \& Roehe P.M. 2002. Caracterização de herpesvírus bovinos tipos 1 (BHV-1) e 5 (BHV-5) com anticorpos monoclonais. Pesq. Vet. Bras. 22(1):13-18.

Straub O.C. 2001. Advances in BHV1 (IBR) Research. Dtsch. Tierärztl. Wochenschr. 108:419-422.

Teixeira M.F.B., Esteves P.A., Coelho C.S.S., da Silva T.C., Oliveira L.G. \& Roehe P.M. 1998. Diferenças em níveis de anticorpos neutralizantes contra herpesvírus bovinos tipos 1 (BHV-1) e 5 (BHV-5). Pesq. Agrop. Gaúcha 4(1):61-65.

Thiry E., Saliki J., Bublot M. \& Pastoret P.P. 1987. Reactivation of infectious bovine rhinotracheitis virus by transport. Comp. Immunol. Microbiol. Infect. Dis. 10(1):59-63.

Thiry J., Widén F., Grégoire F., Linden A., Belák S. \& Thiry E. 2007. Isolation and characterisation of a ruminant alphaherpesvirus closely related to bovine herpesvirus 1 in a free-ranging red deer. BioMed Central Vet. Res. 3(26). doi:10.1186/1746-6148-3-26

Vidor T., Halfen D.C., Leite T.E. \& Coswig L.T. 1995. Herpesvírus bovino tipo 1 (BHV-1): sorologia de rebanhos com problemas reprodutivos. Ciência Rural 25(3):420-424.

Vieira S., Brito W.M.E.D., Souza W.J., Alfaia B.T. \& Linhares D.C.L. 2003. Anticorpos para o herpesvírus bovino 1 (BHV-1) em bovinos do estado de Goiás. Ciência Anim. Bras. 4(2):131-137.

Wizigmann G., Vidor T. \& Ricci Z.M.T. 1972. Investigações sorológicas sobre a ocorrência e incidência dos vírus PI-3, IBR e diarréia a vírus - enfermidade das mucosas dos bovinos no Estado do Rio Grande do Sul. Bolm Inst. Pesq. Vet. Desidério Finamor 1:52-58. 